\title{
Comparative Adsorption of Methylene Blue Dye on Hexane-Washed and Xanthated Spent Grated Coconut (Cocos nucifera L.): Isotherms, Thermodynamics, and Mechanisms
}

\author{
Khadijah Khalid', Megat Ahmad Kamal Megat Hanafiah2 ${ }^{2 *}$, Waheeba A. Al-Amrani ${ }^{3}$, \\ Nik Ahmad Nizam Nik Malek ${ }^{4}$, Sharon Fatinathan ${ }^{5}$ \\ 1 Faculty of Applied Sciences, Universiti Teknologi MARA, 96400 Mukah, Sarawak, Malaysia \\ 2 Faculty of Applied Sciences, Universiti Teknologi MARA, 26400 Jengka, Pahang, Malaysia \\ ${ }^{3}$ Department of Chemistry, Faculty of Science, Ibb University, Ibb, Yemen \\ ${ }^{4}$ Department of Biosciences, Faculty of Science, Universiti Teknologi Malaysia, 81310, Johor Bharu, Malaysia \\ ${ }^{5}$ Faculty of Pharmacy and Health Sciences, Royal College of Medicine Perak, Universiti Kuala Lumpur, 30450 \\ Ipoh, Perak, Malaysia \\ * Corresponding author's e-mail: makmh@uitm.edu.my
}

\begin{abstract}
A batch system investigated the application of two types of chemically modified biosorbents derived from spent grated coconut (Cocos nucifera) powder to adsorb methylene blue (MB) from aqueous solutions. The biosorbents were characterised by spectroscopic and quantitative analyses. The assessment of MB adsorption onto the investigated biosorbents was studied at different experimental conditions with different pHs (2-9) and different initial concentrations of MB (10-400 mg/L) at three different temperatures $(298,308$, and $318 \mathrm{~K})$. The maximum adsorption capacity $\left(\mathrm{q}_{\max }\right)$ of xanthated spent grated coconut (XSGC) was higher than that of hexane-washed spent grated coconut (HSGC). The thermodynamic study indicated that the MB adsorption process was spontaneous for both biosorbents. Desorption of MB-loaded biosorbents was carried out using $\mathrm{HCl}, \mathrm{NaOH}$, and $\mathrm{Na}_{2} \mathrm{EDTA}$ solutions. A desorption ratio of more than $90 \%$ was obtained over three adsorption/desorption cycles for HSGC. However, XSGC demonstrated poor MB desorption, implying a stronger MB interaction with XSGC, which could be attributed to H-bonding, Yoshida H-bonding, $n-\pi$, and $\pi-\pi$ bonding. The study showed that HSGC and XSGC could be applied as biosorbents to remove low MB concentrations from aqueous solutions.
\end{abstract}

Keywords: adsorption, isotherm, mechanism, methylene blue, spent grated coconut.

\section{INTRODUCTION}

Water pollution caused by the excessive release of dyes into bodies of water remains a severe environmental and public problem, particularly since scientists discovered synthetic dyes. Synthetic dyes are known as recalcitrant organic compounds, and they are toxic or carcinogenic. Methylene blue (MB) is an example of a cationic dye commonly used in the textile, paper, leather, plastic, and rubber industries. It is also used as a staining agent in surgery and diagnostic examinations. Other medical applications include treatments for methaemoglobinaemia and cyanide poisoning (Rekha Singh et al., 2020). The presence of MB in wastewater can reduce sunlight penetration into waters, inhibit photosynthesis, impede growth, and increase the toxicity of aquatic biota.

Moreover, $\mathrm{MB}$ is responsible for human health problems such as allergic dermatitis, eye irritation, mutagenicity, and carcinogenesis (Gregorio et al., 2019). Therefore, there is an urgent need to install wastewater treatment systems to treat the dye-bearing wastewater before it is discharged directly into the environment to prevent further contamination. The adsorption technique 
using solid materials can be used to remove dyes from wastewater due to its ease of operation, low cost, and simplicity (Asem et al., 2009; Salahshoor and Shahbazi, 2014). Several MB adsorption studies have been reported using various low-cost biosorbents such as peanut stick wood (Ghaedi et al., 2013), spent grated coconut (Khalid et al., 2015), black cumin seed (Siddiqui et al., 2018), fly ash (Yuan et al., 2019), tea (Lee et al., 2019), black tea powder (Lim et al., 2020), and Ginkgo biloba leaves (Rekha Singh et al., 2020). However, as a model of cationic dye, the treatment of spent grated coconut (SGC) with hexane and carbon disulfide has not been investigated for the adsorption of MB-bearing wastewaters.

In this study, the SGC powder was prewashed with hexane prior to being treated with the xanthation process. The biosorbents were characterised using spectroscopic and quantitative analyses. The MB adsorption onto the biosorbents was elucidated under various experimental conditions, including different $\mathrm{pHs}$, initial MB concentrations, and temperatures. Kinetics and thermodynamic considerations were identified. The mechanisms involved in the MB adsorption process onto biosorbents were also proposed.

\section{MATERIAL AND METHODS}

\section{Sampling and pretreatment}

The raw SGC sample was obtained from a food factory in Kuching, Malaysia. The SGC was screw pressed to remove coconut milk, washed with distilled water, and dried overnight in an oven at $333 \mathrm{~K}$. SGC was pretreated with hexane-washed according to the method used in the previous study (Khalid and Hanafiah, 2014) and labelled as HSGC. The powder was sieved to a particle size of $125-250 \mu \mathrm{m}$ on average. The xanthation treatment of HSGC was performed using carbon disulfide $\left(\mathrm{CS}_{2}\right)$, as previously reported (Khalid and Hanafiah, 2018), and was designated as XSGC.

\section{Characterisation of HSGC and XSGC}

The functional groups of HSGC and XSGC were analysed using a Spectrum 100 Fourier transform infrared (FTIR) spectrometer in the range of $400-4000 \mathrm{~cm}^{-1}$ (PerkinElmer, USA). Both adsorbents were FTIR analysed before and after MB adsorption. The Brunauer-Emmett-Teller (BET) and Langmuir surface $\left(\mathrm{S}_{\mathrm{L}}\right)$ areas of biosorbents were determined from the nitrogen $\left(\mathrm{N}_{2}\right)$ adsorption-desorption curve at $77 \mathrm{~K}$ (Thermo Scientific, Surfer, Italy), respectively. The biosorbents were degassed overnight at $378 \mathrm{~K}$ to remove any physisorbed gases. The $\mathrm{N}_{2}$ adsorption-desorption curve was plotted for each biosorbent, and the surface area was calculated using the BET equation. Table 1 shows the carbon, hydrogen, nitrogen, oxygen, and sulfur (CHNOS) content, $\mathrm{pH}$ point of zero charge $\left(\mathrm{pH}_{\mathrm{pzc}}\right)$, and $\mathrm{pH}_{\text {slurry }}$ of both biosorbents reported in previous work (Khalid and Hanafiah, 2018).

\section{Preparation of MB stock solution and concentration measurements}

MB powder ( $82 \%$ purity) of analytical reagent grade (QRec, Malaysia) was used to prepare a $1000 \mathrm{mg} / \mathrm{L}$ of MB solution by dissolving $1.357 \mathrm{~g}$ of $\mathrm{MB}$ in $1 \mathrm{~L}$ of distilled water. Dilute solutions of the required $\mathrm{MB}$ concentrations were freshly prepared for the subsequent batch adsorption experiments. The concentration of MB was measured using a UV-Visible Spectrophotometer (UV-1800, Shimadzu, Japan) at $\lambda_{\max }$ of $664 \mathrm{~nm}$. The amount of MB adsorbed on the biosorbents was determined using Eq. (1):

$$
\mathrm{q}_{\mathrm{e}}=\frac{\mathrm{C}_{\mathrm{o}}-\mathrm{Ce}_{\mathrm{e}}}{\mathrm{m}} \cdot \mathrm{V}
$$

where: $\mathrm{C}_{\mathrm{o}}$ and $\mathrm{C}_{\mathrm{e}}$ are the $\mathrm{MB}$ concentrations $(\mathrm{mg} / \mathrm{L})$ before and after adsorption, respectively; $\mathrm{V}$ is the volume of MB solution $(\mathrm{L})$, and $\mathrm{m}$ is the weight of the biosorbent (g).

The adsorption experiments were performed in duplicate, and the results were reported as an average with a relative standard deviation (RSD) of $<3 \%$.

\section{Batch adsorption experiments}

\section{Effect of $p H$}

The effect of solution $\mathrm{pH}$ on the adsorption of MB onto HSGC and XSGC was investigated at $\mathrm{pH}$ ranging from 2 to 9 . The $\mathrm{pH}$ of the $\mathrm{MB}$ solution was adjusted by adding $0.10 \mathrm{M} \mathrm{HCl}$ or $\mathrm{NaOH}$. In different conical flasks, $0.03 \mathrm{~g}$ of biosorbent was mixed with $50 \mathrm{~mL}(20 \mathrm{mg} / \mathrm{L})$ of MB solution. The mixture was stirred at 480 
rpm for $300 \mathrm{~min}$ at $298 \mathrm{~K}$. The mixture was centrifuged at $5000 \mathrm{rpm}$ for $5 \mathrm{~min}$ to separate the MB-loaded biosorbent, and the supernatant was determined spectrophotometrically.

\section{Isotherm and thermodynamic studies}

Adsorption isotherms were measured at 298, 308 , and $318 \mathrm{~K}$ with $\mathrm{MB}$ concentrations ranging from 10 to $400 \mathrm{mg} / \mathrm{L}$. The biosorbent dosage was fixed at $0.03 \mathrm{~g}$, and the mixture was stirred at 480 rpm for 300 min while the $\mathrm{pH}$ of the solution was kept at 6 . The Langmuir (Langmuir, 1916) and Freundlich (Freundlich, 1906) equations were used to analyse the data. The linear Langmuir equation is given by Eq. (2):

$$
\frac{\mathrm{C}_{\mathrm{e}}}{\mathrm{q}_{\mathrm{e}}}=\frac{1}{\mathrm{q}_{\max } \mathrm{b}}+\frac{\mathrm{C}_{\mathrm{e}}}{\mathrm{q}_{\max }}
$$

where: $q_{e}$ is the adsorption capacity at equilibrium $(\mathrm{mg} / \mathrm{g}), \mathrm{q}_{\max }$ is the maximum adsorption capacity $(\mathrm{mg} / \mathrm{g}$ ), and $\mathrm{b}$ is the Langmuir constant $(\mathrm{L} / \mathrm{mg}$ or $\mathrm{L} / \mathrm{mol}$ ) related to the energy of adsorption, which reflects the affinity of the biosorbent for the adsorbate species.

The values of Langmuir constants $\left(\mathrm{q}_{\max }\right.$ and b) were calculated from the slopes and intercepts of the straight lines of the experimental data plots of MB adsorption, respectively. The linear Freundlich model is given by Eq. (3):

$$
\log \mathrm{q}_{\mathrm{e}}=\log \mathrm{K}_{\mathrm{F}}+\frac{1}{n} \log \mathrm{C}_{\mathrm{e}}
$$

where: $\mathrm{K}_{\mathrm{F}}$ represents Freundlich constant related to maximum adsorption capacity $(\mathrm{mg} / \mathrm{g})$, and $\mathrm{n}$ is the adsorption intensity (unitless).

The Freundlich values $\left(1 / \mathrm{n}\right.$ and $\left.\mathrm{K}_{\mathrm{F}}\right)$ were calculated from the slopes and intercepts of the straight lines in the MB adsorption experimental data, respectively. The thermodynamic studies examined the enthalpy change $\left(\Delta \mathrm{H}^{\circ}\right)$, entropy change $\left(\Delta S^{\circ}\right)$, and Gibbs free energy change $\left(\Delta \mathrm{G}^{\mathrm{o}}\right)$. All thermodynamics parameters can be calculated from Eqs. (4) and (5):

$$
\begin{gathered}
\Delta \mathrm{G}^{\mathrm{o}}=-\mathrm{RT} \ln \mathrm{k}_{\mathrm{L}} \\
\ln \mathrm{k}_{\mathrm{L}}=\Delta \mathrm{S}^{\mathrm{o}} / \mathrm{R}-\Delta \mathrm{H}^{\mathrm{o}} / \mathrm{RT}
\end{gathered}
$$

where: $\mathrm{R}$ is the universal gas constant $(8.314 \mathrm{~J} / \mathrm{mol}$ $\mathrm{K}), \mathrm{k}_{\mathrm{L}}$ is the Langmuir constant $(\mathrm{L} / \mathrm{mol})$, and $\mathrm{T}$ is the temperature in $\operatorname{Kelvin}(\mathrm{K}), \Delta \mathrm{S}^{\mathrm{o}}$ and $\Delta \mathrm{H}^{\circ}$ are calculated from the intercept and slope of the plot of $\ln \mathrm{k}_{\mathrm{L}}$ versus $1 / \mathrm{T}$.

\section{Desorption study}

The disposal of the exhausted loaded biosorbent may cause another environmental issue. Consequently, regeneration of the exhausted biosorbent via desorption was investigated in this study using three eluents $(\mathrm{HCl}, \mathrm{NaOH}$, or $\mathrm{Na}_{2}$ EDTA) at different concentrations. First, the biosorbent was loaded with $\mathrm{MB}$ as follows: At $\mathrm{pH}$ 6, $0.03 \mathrm{~g}$ of biosorbent was mixed with $50 \mathrm{~mL}$ of $10 \mathrm{mg} / \mathrm{L} \mathrm{MB}$ solution. The mixture was stirred at $480 \mathrm{rpm}$ for $300 \mathrm{~min}$ at $298 \mathrm{~K}$. The mixture was then centrifuged to separate the MB-loaded biosorbent prior to being ovendried at $333 \mathrm{~K}$ for $1 \mathrm{~h}$. The centrifuged MB solution was measured spectroscopically. The dried biosorbent was transferred into different conical flasks $(100 \mathrm{~mL})$, and $50 \mathrm{~mL}$ of $(0.001$, $0.005,0.010,0.050$, and $0.100 \mathrm{M}$ ) of eluents were added independently. The mixtures were stirred at $298 \mathrm{~K}$ and $480 \mathrm{rpm}$ for $300 \mathrm{~min}$. The mixtures were then centrifuged, and the MB desorbed was calculated using Eq. (6):

$$
\text { Desorption }(\%)=\frac{\text { Total adsorption capacity after elution }}{\text { Total adsorption capacity before elution }} \times 100
$$

\section{Regeneration}

A conical flask $(100 \mathrm{~mL})$ was filled with $50 \mathrm{~mL}$ of $\mathrm{MB}$ solution $(10 \mathrm{mg} / \mathrm{L})$ and $0.03 \mathrm{~g}$ biosorbent. The mixture was stirred at $480 \mathrm{rpm}$ for $120 \mathrm{~min}$ at $298 \mathrm{~K}$. The mixture was centrifuged at $5000 \mathrm{rpm}$ for $5 \mathrm{~min}$ to separate the MB-loaded biosorbent from the solution. The centrifuged MB solution was measured spectroscopically. The biosorbent was oven dried for $1 \mathrm{~h}$ at $333 \mathrm{~K}$. The dried biosorbent was then transferred to another conical flask $(100 \mathrm{~mL})$, and $50 \mathrm{~mL}$ of $0.10 \mathrm{M} \mathrm{HCl}$ was added. Based on the results of the desorption study, $0.10 \mathrm{M}$ $\mathrm{HCl}$ was chosen as the eluent for regeneration of the MB-loaded biosorbents. The mixture was stirred again for $120 \mathrm{~min}$ at $298 \mathrm{~K}$ and 480 rpm to desorb the MB ions. The mixture was centrifuged, and the amount of desorbed MB was measured. The biosorbent was rewashed with $50 \mathrm{~mL}$ of distilled water to remove excess acid prior to oven-dried at $333 \mathrm{~K}$ for $1 \mathrm{~h}$. The biosorbent was mixed again with $50 \mathrm{~mL}(10$ $\mathrm{mg} / \mathrm{L}$ ) of MB solution, and the above procedure was repeated twice. 


\section{RESULTS AND DISCUSSION}

\section{Characterisation of biosorbents}

Table 1 presents the BET and $\mathrm{S}_{\mathrm{L}}$ values, with the lower values for BET and $S_{L}$ for the XSGC being relative to the HSGC.

This could be attributed to the opening of one or more pores following treatment with a strong base $(\mathrm{NaOH})$ and the presence of carbonoxygen-sulphur functional groups, which occupy a significant portion of the biosorbent surface (Youssef et al., 1995). The elemental compositions (CHNOS) of HSGC and XSGC were reported to have changed after xanthate chemical modification in a previous study (Khalid and Hanafiah, 2018). The carbon content decreased by $4.09 \%$ for XSGC. Instead, the oxygen content of XSGC increased by $6.32 \%$.

Furthermore, the xanthation process was able to increase the sulphur content of XSGC by $0.24 \%$. This confirmed the successful introduction of the sulphur bearing group via the xanthation process. The nitrogen content of XSGC was lower than that of HSGC in the previous study. As shown in Table 1, the previous finding discovered that the $\mathrm{pH}_{\text {slurry }}$ and $\mathrm{pH}_{\mathrm{pzc}}$ values for XSGC are higher than those for HSGC (Khalid and Hanafiah, 2018). This meant that the number of acidic sites had decreased while the number of basic sites had increased. This implied that the xanthation process had successfully altered the biosorbent's surface properties.

Figure 1 depicts the FTIR spectra of HSGC and XSGC (before and after MB adsorption). Both biosorbents had nearly identical peaks detected at $2800 \mathrm{~cm}^{-1}$ to $3400 \mathrm{~cm}^{-1}$, representing the $-\mathrm{C}-\mathrm{H},-\mathrm{CO}-\mathrm{H}$, and $-\mathrm{NH}_{2}$ stretching regions,

Table 1. Physicochemical properties of HSGC and XSGC

\begin{tabular}{|c|c|c|}
\hline Analysis & HSGC & XSGC \\
\hline $\mathrm{S}_{\text {BET }}\left(\mathrm{m}^{2} / \mathrm{g}\right)$ & 19.17 & 13.15 \\
\hline $\mathrm{S}_{\mathrm{L}}\left(\mathrm{m}^{2} / \mathrm{g}\right)$ & 194.10 & 151.4 \\
\hline${\text { Carbon }(\%)^{\mathrm{a}}}^{\mathrm{a}}$ & 42.37 & 38.28 \\
\hline Hydrogen (\%) $)^{\mathrm{a}}$ & 7.77 & 7.41 \\
\hline Nitrogen (\%) & 2.23 & 0.12 \\
\hline Sulphur $(\%)^{\mathrm{a}}$ & 0.18 & 0.42 \\
\hline${\text { Oxygen }(\%)^{\mathrm{a}}}^{2}$ & 47.45 & 53.77 \\
\hline $\mathrm{pH}_{\text {slurr }}{ }^{\mathrm{a}}$ & 6.00 & 6.53 \\
\hline $\mathrm{pH}_{\mathrm{pzc}}{ }^{\mathrm{a}}$ & 6.42 & 6.75 \\
\hline aSource: Khalid and Hanafiah, 2018. \\
\hline
\end{tabular}

as shown in Figure 1A. However, the differences were typically below the wavenumber of $1750 \mathrm{~cm}^{-1}$, confirming the success of the chemical modification process. XSGC shows a broad peak at $3383 \mathrm{~cm}^{-1}$ prior to MB adsorption, indicating that the hydroxyl groups have combined with $\mathrm{CS}_{2}$. Moreover, since the adsorption occurs in the same region, the peaks at $1547 \mathrm{~cm}^{-1}$, $1322 \mathrm{~cm}^{-1}$, and $1252 \mathrm{~cm}^{-1}$ were attributed to $\mathrm{C}=\mathrm{S}$ stretching vibrations and their significant interactions with $\mathrm{C}-\mathrm{O}$ and $\mathrm{C}-\mathrm{N}$ stretching (Silverstein et al., 2005). Peaks at $1087 \mathrm{~cm}^{-1}$ and $1030 \mathrm{~cm}^{-1}$ indicated the presence of $\mathrm{C}=\mathrm{S}$ groups in addition to C-O-C groups from polymeric cellulose, hemicellulose, or lignin.

Wavenumbers in HSGC shifted from 3431 $\mathrm{cm}^{-1}$ to $3207 \mathrm{~cm}^{-1}$ after MB adsorption, while XSGC shifted from $3383 \mathrm{~cm}^{-1}$ to $3411 \mathrm{~cm}^{-1}$ (Figure 1B). This implied (i) the formation of $\mathrm{H}$-bonding between -OH functional groups of the biosorbent surface as the H-donor and atoms such as nitrogen in $\mathrm{MB}$ molecules as the $\mathrm{H}$-acceptor atom (also known as dipole-dipole H-bonding) and (ii) the $-\mathrm{OH}$ functional groups of the adsorbents $(\mathrm{H}-$ donor) could interact with the $\pi$-electron clouds of the aromatic rings (H-acceptor) thus forming the H-bonding (also known as the Yoshida Hbonding) (Tran et al., 2017).

A visible difference was initially observed in the $1746 \mathrm{~cm}^{-1}$ region of XSGC but interestingly was found to vanish after MB adsorption. This implied that (iii) the $n-\pi$ interactions from the biosorbent surface's carbonyl functional groups act as electron donors, and the aromatic rings of $\mathrm{MB}$ act as the electron acceptors had decreased in intensity or shifted after MB adsorption.

Another interesting observation could be made in the aromatic group's $\mathrm{C}=\mathrm{C}$ region and the $\mathrm{C}=\mathrm{N}$ vibration. These peaks had higher intensities and shifted from $1648 \mathrm{~cm}^{-1}$ to 1636 and 1608 $\mathrm{cm}^{-1}$ in XSGC. This significantly proved that (iv) the $\pi-\pi$ interaction occurred between the MB and its aromatic moiety, and $\mathrm{C}=\mathrm{N}$ heterocyclic was abundant on the biosorbent surface. Furthermore, biosorbents exhibited medium to strong peaks ranging from 1384 to $1385 \mathrm{~cm}^{-1}$, which could be attributed to the symmetrical and asymmetrical bending vibrations of $-\mathrm{CH}_{3}$ in $\mathrm{MB}$ molecules (Ovchinnikov et al., 2016). Figure 2 depicts the MB adsorption mechanisms on both biosorbents. 

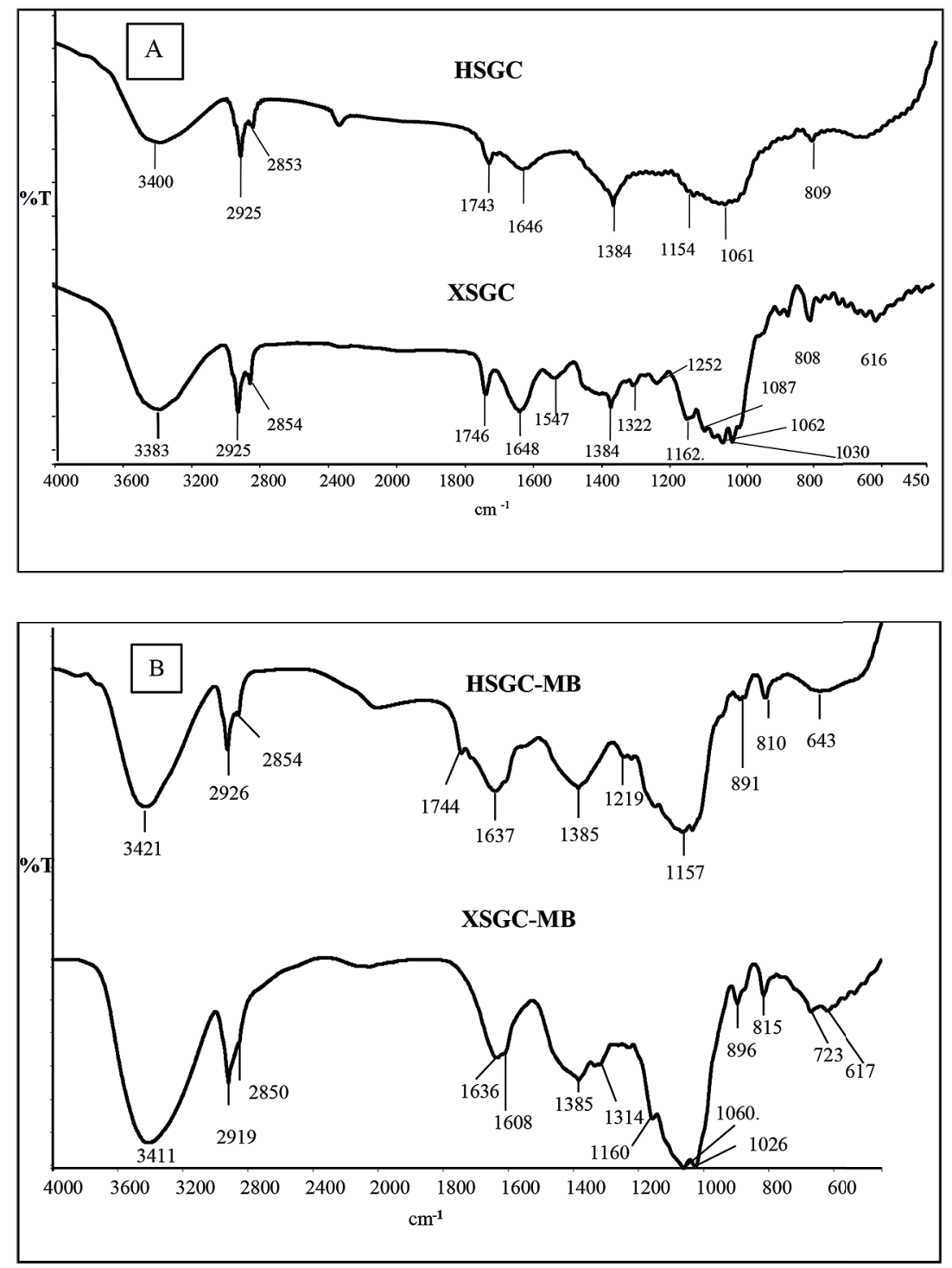

Figure 1. A Comparison of FTIR Spectra of HSGC and XSGC (A) before MB loaded (A) and (B) after MB loaded

\section{Effect of $\mathrm{pH}$}

The effect of $\mathrm{pH}$ on $\mathrm{MB}$ adsorption onto HSGC and XSGC biosorbents was investigated at $298 \mathrm{~K}$, as shown in Figure 3.

It was observed that $\mathrm{MB}$ biosorption increased as the $\mathrm{pH}$ of the solution approached $\mathrm{pH}_{\mathrm{pzc}}$. Beyond that point, the HSGC showed significantly higher MB uptake than the XSGC in the $\mathrm{pH}$ range of 5 to 9 . The decrease in MB adsorption capacity at $\mathrm{pH}<5$ could be attributed to the $\mathrm{H}^{+}$ion saturation of the investigated biosorbent surface. The number of negative sites exposed to the MB molecules increases as the $\mathrm{pH}$ increases, allowing for more electrostatic interaction. A similar observation was previously reported by Doğan et al. (2009) that increasing the $\mathrm{pH}$ from 3 to 7 enhanced the adsorption capacity of the kenaf core fibres for MB adsorption. In another study, Liu and Jiao (1998) discovered that MB binding was due to electrostatic attractions and Van der Waals forces, whereas ion exchange could be a major mechanism for $\mathrm{MB}$ adsorption onto the biosorbent (Fernandez et al., 2010). According to the overall findings, MB molecules were adsorbed on XSGC via hydrogen bonding, $n-\pi$ and $\pi-\pi$ interactions, and Van der Waals, as proposed in Figure 2.

\section{Isotherm and thermodynamic study}

Figure 4 shows the plots of equilibrium adsorption capacity $(q)$ versus MB concentration in solution. 

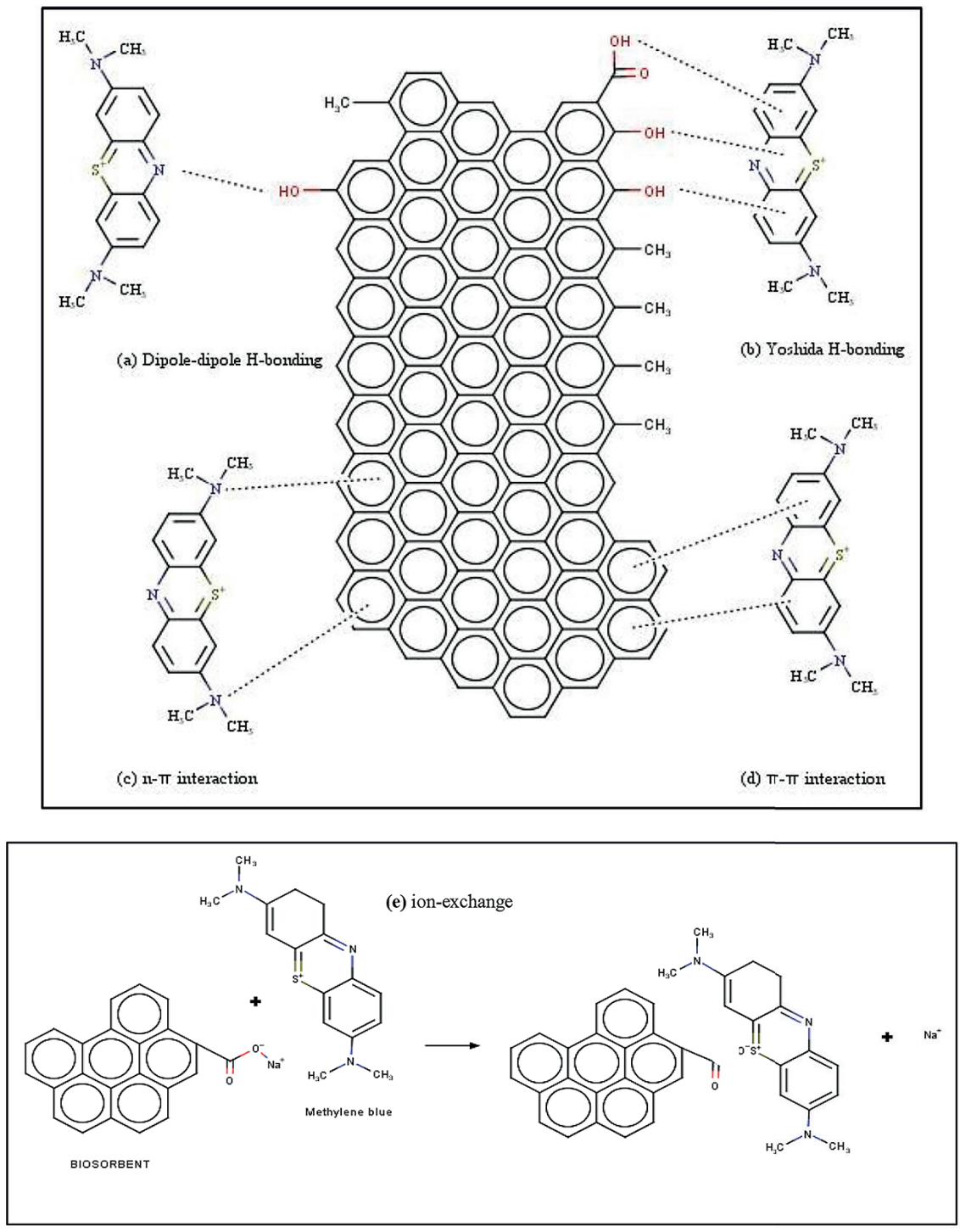

Figure 2. Schematic diagram of MB adsorption mechanisms (a) Dipole-dipole H- bonding; (b) Yoshida H-bonding; (c) $n-\pi$ bonding; (d) $\pi-\pi$ bonding and (e) ion-exchange

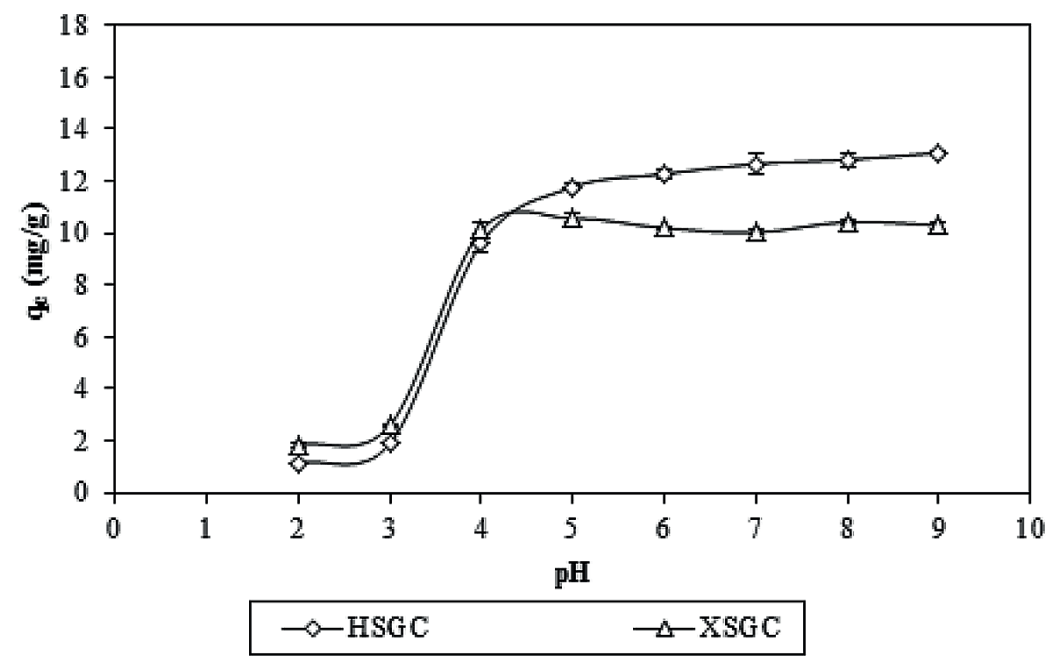

Figure 3. Effect of $\mathrm{pH}$ on MB adsorption onto HSGC and XSGC (Biosorbent weight: $0.03 \mathrm{~g}, \mathrm{pH}: 2-9$, volume: $50 \mathrm{~mL}$, stirring Speed: $480 \mathrm{rpm}, \mathrm{MB}$ concentration: $20 \mathrm{mg} / \mathrm{L}$, contact time: $360 \mathrm{~min}$ ) 

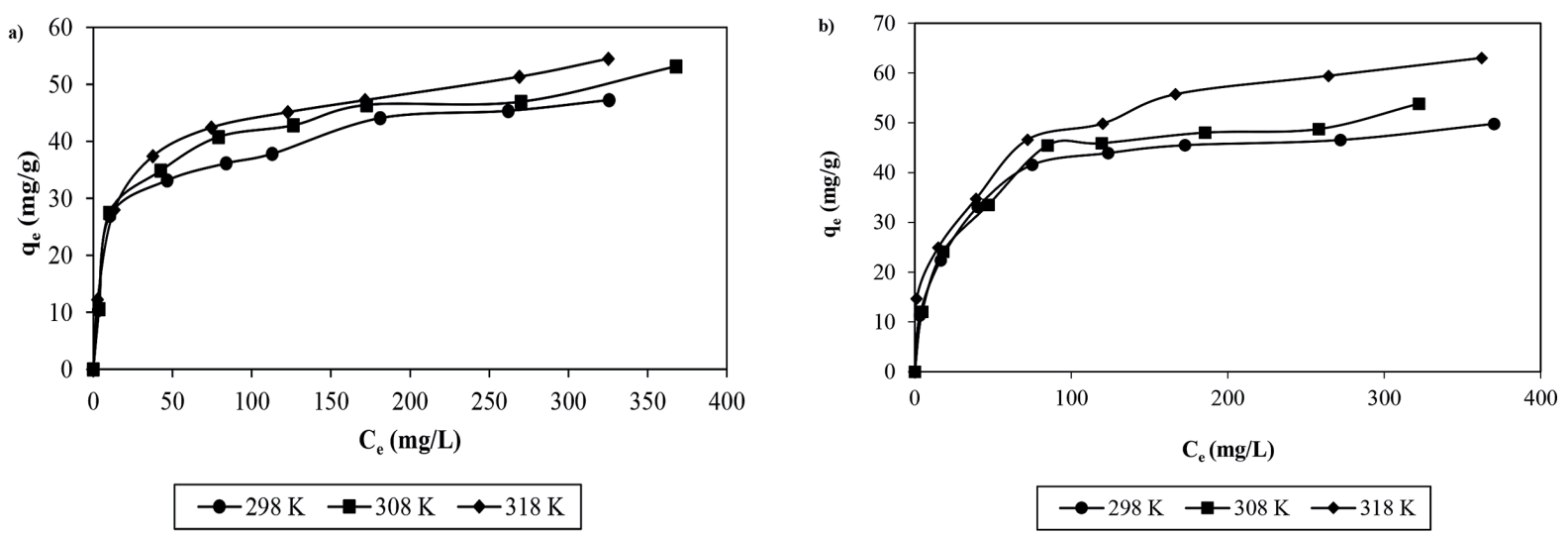

Figure 4. General isotherm plots of MB adsorption by (a) HSGC and (b) XSGC (Biosorbent weight: 0.03 g, pH: 6, volume: $50 \mathrm{~mL}$, stirring speed: $480 \mathrm{rpm}$, concentration: 10-400 mg/L, contact time: $300 \mathrm{~min}$ )

The adsorption capacity increased with increasing initial MB concentrations in both plots until the biosorbents reached near-surface saturation. Besides, as the temperature increased, the adsorption capacity increased slightly, indicating an endothermic reaction. Furthermore, the HSGC and XSGC plots revealed the " $\mathrm{L}$ " isotherm type as defined by the Giles classification system (Giles et al., 1960). The experimental data were fitted to the Langmuir and Freundlich linear isotherm models. Table 2 shows the constants for each isotherm model calculated at different temperatures.

Table 2 shows that the $\mathrm{R}^{2}$ values for both biosorbents were close to unity, with $\mathrm{R}^{2}>0.99$, and that the $\mathrm{q}_{\text {cal.max }}$ was very close to the $\mathrm{q}_{\text {exp.max }}$ at all temperatures. Therefore, MB adsorption onto both biosorbents followed Langmuir's assumption of monolayer and homogeneous distribution onto energetically equivalent biosorption sites.

Table 2 also shows that the $\mathrm{R}^{2}$ values for the Freundlich isotherm were lower than the Langmuir isotherm, with $\mathrm{R}^{2}<0.95$. The $\mathrm{n}$ values indicated that HSGC and XSGC adsorption was favourable. Furthermore, the $\mathrm{K}_{\mathrm{F}}$ values were significantly lower than the $\mathrm{q}_{\text {exp,max }}$, implying that
MB adsorption was not caused by multilayer adsorption or heterogeneous distribution on biosorbent surface sites. Hence, MB adsorption onto both biosorbents deviated from the Freundlich models. Table 3 compares the adsorption capacity values obtained for HSGC and XSGC with those of other natural biosorbents. It can be concluded that HSGC and XSGC performed better than other high surface area biosorbents such as activated carbons, and thus HSGC and XSGC can be used as alternative biosorbents in removing low $\mathrm{MB}$ concentrations from aqueous solutions.

Table 4 shows the thermodynamic parameters $\Delta \mathrm{G}^{\circ}(\mathrm{kJ} / \mathrm{mol}), \Delta \mathrm{H}^{\circ}(\mathrm{kJ} / \mathrm{mol})$, and $\Delta \mathrm{S}^{\circ}(\mathrm{J} / \mathrm{K} \cdot \mathrm{mol})$. The negative values of $\Delta \mathrm{H}^{\circ}$ for $\mathrm{MB}$ adsorption onto XSGC indicated exothermic adsorption, whereas MB adsorption onto HSGC indicated endothermic adsorption. In comparison to XSGC, the positive value of $\Delta \mathrm{H}^{\circ}$ for $\mathrm{HSGC}$ reflected by increased temperature could be due to a swelling effect within the internal structure of the biosorbent and enlargement of pore size, allowing a dye molecule to diffuse and adsorbed on the active site. The negative value of $\Delta \mathrm{S}^{\circ}$ for XSGC, on the other hand, reflects the system's decrease of

Table 2. Langmuir and Freundlich isotherm constants and correlation coefficients of MB adsorption onto HSGC and XSGC

\begin{tabular}{|c|c|c|c|c|c|c|c|c|}
\hline \multirow{3}{*}{ Biosorbents } & \multicolumn{9}{|c|}{ Langmuir } & \multicolumn{3}{c|}{ Freundlich } \\
\cline { 2 - 10 } & $\mathrm{T}(\mathrm{K})$ & $\begin{array}{c}\mathrm{q}_{\text {exp.max }} \\
(\mathrm{mg} / \mathrm{g})\end{array}$ & $\begin{array}{c}\mathrm{q}_{\text {cal'max }} \\
(\mathrm{mg} / \mathrm{g})\end{array}$ & $\begin{array}{c}\mathrm{b} \\
(\mathrm{L} / \mathrm{mg})\end{array}$ & $\mathrm{R}^{2}$ & $\mathrm{n}$ & $\mathrm{R}^{2}$ & $\begin{array}{c}\mathrm{K}_{\mathrm{F}} \\
(\mathrm{mg} / \mathrm{g})\end{array}$ \\
\hline \multirow{3}{*}{ HSGC } & 298 & 45.36 & 47.33 & 0.06 & 0.993 & 3.38 & 0.875 & 0.99 \\
\cline { 2 - 10 } & 308 & 46.96 & 49.16 & 0.07 & 0.998 & 3.22 & 0.862 & 0.99 \\
\cline { 2 - 10 } & 318 & 51.35 & 52.77 & 0.07 & 0.997 & 3.36 & 0.929 & 0.93 \\
\hline \multirow{3}{*}{ XSGC } & 298 & 49.79 & 50.51 & 0.07 & 0.996 & 3.22 & 0.940 & 0.96 \\
\cline { 2 - 10 } & 308 & 53.83 & 54.35 & 0.06 & 0.992 & 2.92 & 0.942 & 0.92 \\
\cline { 2 - 10 } & 318 & 63.02 & 64.52 & 0.05 & 0.990 & 3.72 & 0.984 & 1.13 \\
\hline
\end{tabular}


Table 3. Comparison of HSGC and XSGC adsorption capacities for MB with other biosorbents

\begin{tabular}{|l|c|c|l|}
\hline \multicolumn{1}{|c|}{ Biosorbents } & $\begin{array}{c}\mathrm{q}_{\text {cal.max }} \\
(\mathrm{mg} / \mathrm{g})\end{array}$ & Temperature $(\mathrm{K})$ & \multicolumn{1}{|c|}{ Reference } \\
\hline HSGC & 52.77 & 318 & This work \\
\hline XSGC & 64.52 & 318 & This work \\
\hline Cashew nut testa tannin resin & 17.86 & 303 & Nnaji et al. (2021) \\
\hline Waste activated carbon & 15.38 & 333 & Mishra et al. (2021) \\
\hline Wood apple rind activated carbon & 40.10 & NA & Malarvizhi and Ho (2010) \\
\hline Leaves of Solanum tuberosum & 52.60 & 303 & Gupta et al. (2021) \\
\hline Stem of Solanum tuberosum & 41.60 & 303 & Gupta et al. (2021) \\
\hline Seeds of Citrullus colocynthis & 18.83 & 333 & Alghamdi and El Mannoubi (2021) \\
\hline
\end{tabular}

NA - not available.

randomness due to the strong binding of dye molecules on XSGC compared to HSGC. The data given in Table 4 showed that $\left|\Delta \mathrm{H}^{\circ}\right|<\left|\mathrm{T} \Delta \mathrm{S}^{\circ}\right|$ for both biosorbents at all temperatures. This indicated that entropic rather than enthalpic changes dominated the adsorption process (Asem et al., 2009). The negative $\Delta G^{\circ}$ values reported in Table 4 indicated that MB adsorption on HSGC and XSGC was spontaneous. Similar findings were obtained with bamboo charcoal, which reported that MB adsorption was a spontaneous, endothermic process with an increase in randomness at the solid/solution interface (Nnaji et al., 2021).

\section{Desorption study}

Figure 5 depicts the percentage of desorption versus various concentrations of three desorbing solutions: $\mathrm{HCl}, \mathrm{NaOH}$, and $\mathrm{Na}_{2}$ EDTA solutions.

The percentage of desorption for $\mathrm{HCl}$ solution was very high (71.7-100\%), followed by $\mathrm{Na}_{2} \mathrm{EDTA}(3.5-14.6 \%$ ), and the lowest for $\mathrm{NaOH}$ solution $(2.6-3.2 \%)$. $\mathrm{HCl}$ was able to desorb MB from HSGC completely when used at a higher concentration $(0.10 \mathrm{M})$. These findings could imply that ion exchange was important in MB adsorption onto HSGC because the strong

Table 4. Thermodynamic parameters of MB adsorption

\begin{tabular}{|c|c|c|c|c|}
\hline Biosorbents & $\mathrm{T}(\mathrm{K})$ & $\begin{array}{c}\Delta \mathrm{G}^{\circ}(\mathrm{kJ} / \\
\mathrm{mol})\end{array}$ & $\begin{array}{c}\Delta \mathrm{H}^{\circ}(\mathrm{kJ} / \\
\mathrm{mol})\end{array}$ & $\begin{array}{c}\Delta \mathrm{S}^{\circ} \mathrm{J} / \\
(\mathrm{K} . \mathrm{mol})\end{array}$ \\
\hline \multirow{3}{*}{$\mathrm{HSGC}$} & 298 & -24.11 & +5.61 & +100.10 \\
\cline { 2 - 5 } & 308 & -25.43 & & \\
\cline { 2 - 5 } & 318 & -26.10 & & \\
\hline \multirow{3}{*}{ XSGC } & 298 & -24.42 & -11.53 & -43.13 \\
\cline { 2 - 5 } & 308 & -24.73 & & \\
\cline { 2 - 5 } & 318 & -25.29 & & \\
\hline
\end{tabular}

acid could aid in the recovery of the dye ion. The MB molecules could not be desorbed by a strong base $(\mathrm{NaOH})$. This result was consistent with the findings of a previous study (Zhu et al., 2009), which found that very little desorption occurred in the desorption experiment using $\mathrm{NaOH}$ (yield $1.64 \%$ ), and $0.1 \mathrm{~N} \mathrm{HCl}$ (yield 2.64\%). However, all eluents were ineffective in removing the $\mathrm{MB}$ from the XSGC biosorbent. The low XSGC desorption suggested that $\mathrm{MB}$ had a strong interaction with the XSGC surface, making removal extremely difficult.

\section{Regeneration}

The desorption study justifies to use of $0.1 \mathrm{M}$ $\mathrm{HCl}$ for the regeneration of the MB-loaded biosorbent. Three regeneration cycles of MB-loaded biosorbents were performed, and the results are shown in Table 5. The results showed that the percentage of MB adsorption and desorption decreased with each regeneration cycle. Except for XSGC, regeneration of MB-loaded HSGC using $0.1 \mathrm{M} \mathrm{HCl}$ was satisfactory, as evidenced by high desorption rates even after the third cycle. The high percentage of MB desorbed and adsorbed for HSGC was due to (i) the weak intermolecular

Table 5. Three cycle regeneration of MB using $0.1 \mathrm{M}$ $\mathrm{HCl}$ solution

\begin{tabular}{|c|c|c|c|}
\hline \multirow{2}{*}{ Biosorbents } & \multirow{2}{*}{ Cycle } & \multicolumn{2}{|c|}{ MB } \\
\cline { 3 - 4 } & & $\begin{array}{c}\text { Adsorption } \\
(\mathrm{mg} / \mathrm{L})\end{array}$ & $\begin{array}{c}\text { Desorption } \\
(\%)\end{array}$ \\
\hline \multirow{3}{*}{ HSGC } & 1 & 32.30 & 100.00 \\
\cline { 2 - 4 } & 2 & 29.6 & 97.2 \\
\cline { 2 - 4 } & 3 & 26.4 & 92.5 \\
\hline \multirow{3}{*}{ XSGC } & 1 & 2.84 & 8.7 \\
\cline { 2 - 4 } & 2 & 3.17 & 9.8 \\
\cline { 2 - 4 } & 3 & 2.07 & 6.4 \\
\hline
\end{tabular}




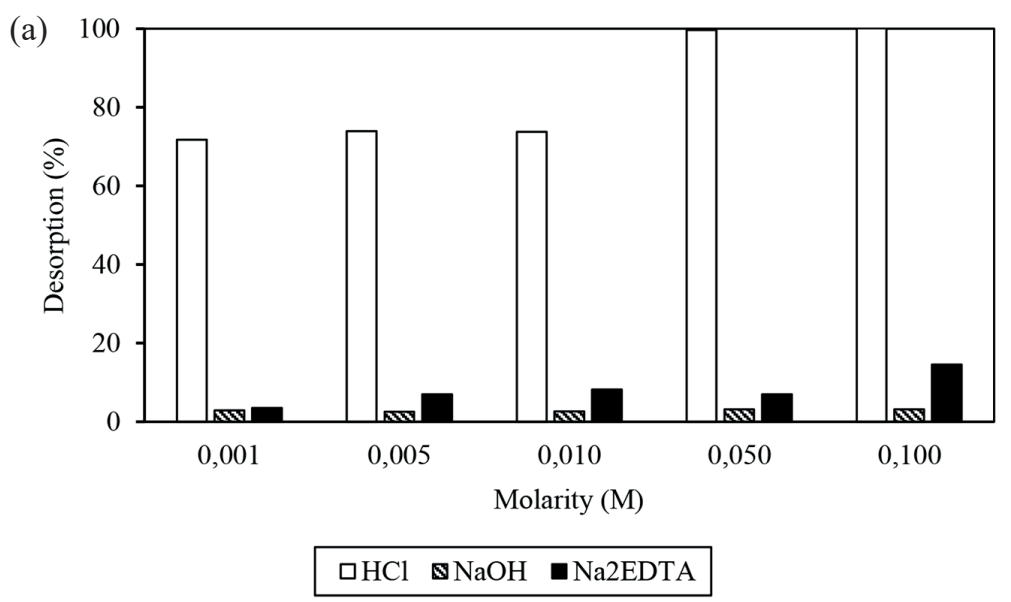

(b)

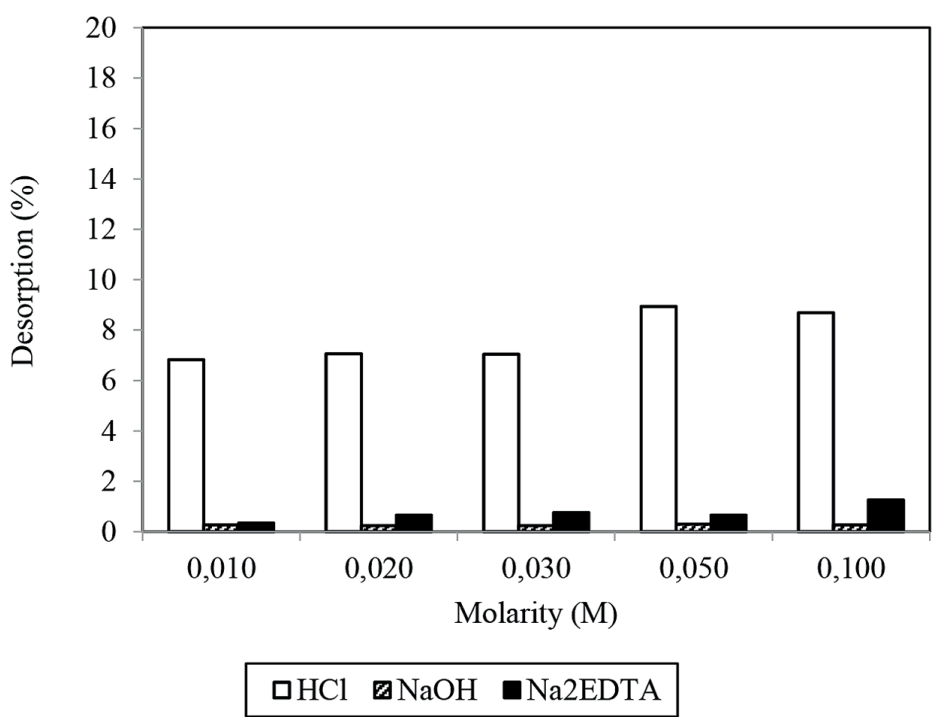

Figure 5. Desorption of $\mathrm{MB}$ by $\mathrm{HCl}, \mathrm{NaOH}$ and $\mathrm{Na}$ EDTA solutions at various concentrations for (a) HSGC and (b) XSGC

attraction of MB to HSGC and (ii) the cationic dye being the predominantly undissociated form at lower pH (Karaoglu et al., 2010).

\section{CONCLUSIONS}

The SGC powder was chemically modified using hexane-washed and xanthation processes to yield two biosorbents, HSGC and XSGC. Both biosorbents' physicochemical characteristics had been successfully altered by the chemical modification. At $\mathrm{pH} 6$, the XSGC had a greater maximum adsorption capacity for MB dye than the HSGC. The results showed that the experimental data fit the Langmuir isotherm model well, with $\mathrm{R}^{2}$ $>0.99$. Thermodynamic studies revealed the adsorption process's feasibility and spontaneity at higher temperatures. According to desorption studies, ion exchange played a significant role in HSGC adsorption compared to XSGC. Therefore, regeneration of the HSGC biosorbent was simple, requiring only $0.1 \mathrm{M}$ $\mathrm{HCl}$ and yielding a $100 \%$ efficiency. Low MB desorption by XSGC implies a stronger MB interaction with XSGC, which could be attributed to H-bonding, Yoshida H-bonding, and $n-\pi$ and $\pi-\pi$ bonding. According to the findings, HSGC and XSGC can be used as biosorbents to remove low MB concentrations from aqueous solutions.

\section{Acknowledgements}

The authors gratefully acknowledge the financial support of the Malaysian Ministry of Higher Education through the Fundamental Research Grant Scheme (FRGS 5/3 (67/2016)). 


\section{REFERENCES}

1. Alghamdi W.M., El Mannoubi I. 2021. Investigation of seeds and peels of Citrullus colocynthis as efficient natural adsorbent for methylene blue dye. Processes, 9, 1279

2. Asem A.A., Ahmed M.D., Waheeba A.A. 2009. Adsorption/desorption behavior of acid orange 10 on magnetic silica modified with amine groups. Chemical Engineering Journal, 150, 55-62.

3. Doğan M., Abak H., Alkan M. 2009. Adsorption of methylene blue onto hazelnut shell: Kinetics, mechanism and activation parameters. Journal of Hazardous Materials, 164, 172-181.

4. Fernandez M.E., Nunell G.V., Bonelli P.R., Cukierman A.L. 2010. Effectiveness of Cupressus pervirens cones as biosorbent for the removal of basic dyes from aqueous solutions in batch and dynamic modes. Bioresource Technology, 101, 9500-9507.

5. Freundlich H.M.F. 1906. Über die in läosungen. Journal of Physical Chemistry, 57, 385-470.

6. Ghaedi M., Nasab A.G., Khodadoust S., Rajabi M., Azizian S. 2013. Application of activated carbon as adsorbents for efficient removal of methylene blue: Kinetics and equilibrium study. Journal of Industrial and Engineering Chemistry, 20, 2317-2324.

7. Giles C.H., Macewan T.H., Nakhwa S.N., Smith D. 1960. Studies in adsorption: Part XI. A system of classifcation of solution adsorption isotherms, and its use in diagnosis of adsorption mechanisms and in measurement of specific surface areas of solids. Journal of the Chemical Society, 14, 3973-3993.

8. Grégorio C., Giangiacomo T., Eric L., George Z.K., Lee D.W., Nadia M.C. 2019. Dye removal by biosorption using cross-linked chitosan-based hydrogels. Environmental Chemistry Letters, 17(4), 1645-1666.

9. Gupta N., Kushwaha A.K., Chattopadhyaya M.C. 2016. Application of potato (Solanum tuberosum) plant wastes for the removal of methylene blue and malachite green dye from aqueous solution. Arabian Journal of Chemistry, 9, 707-716.

10. Karaoglu M.H., Ugurlu M. 2010. Kinetic and equilibrium studies of methylene blue biosorption by vineyard pruning waste. Fresenius Environmental Bulletin, 19(12), 3199-3208.

11. Khalid K., Hanafiah M.A.K.M. 2018. Kinetics, isotherm, thermodynamics, and mechanisms of $\mathrm{Pb}(\mathrm{II})$ adsorption on chemically modified spent grated coconut (Cocos nucifera). Recent Innovations in Chemical Engineering, 11, 201-224.

12. Khalid K., Hanafiah M.A.K.M., Wan Mat Khalir W.K.A. 2015. Effect of physicochemical parameters on methylene blue adsorption by sulfuric acid treated spent grated coconut. Applied Mechanics and Materials, 752-753, 71-76.
13. Khalid K., Hanafiah M.A.K.M. 2014. Kinetic and isotherm adsorption studies of methylene blue on sulfuric acid treated spent grated coconut. Advanced Materials Research, 970, 192-197.

14. Langmuir I. 1916. The constitution and fundamental properties of solids and liquids. Journal of American Chemical Society, 38, 2221-2295.

15. Lee T.C., Wang S., Huang Z., Mo Z., Wang G., Wu Z., Liu C., Han H., Ko T.H. 2019. Tea stem as a sorbent for removal of methylene blue from aqueous phase. Advances in Materials Science and Engineering. Article ID 9723763, 15 pages.

16. Lin D., Wu F., Hu Y., Zhang T., Liu C., Hu Q., Hu Y., Xue Z., Han H., Ko T.H. 2020. Adsorption of dye by waste black tea powder: Parameters, kinetic, equilibrium, and thermodynamic studies. Journal of Chemistry. Article ID 5431046, 13 pages.

17. Liu Q., Jiao Q. 1998. Mechanism of methylene blue action and interference in the heparin assay. Spectroscopy Letters, 31, 913-924.

18. Malarvizhi R., Ho Y.S. 2010. The influence of $\mathrm{pH}$ and the structure of the dye molecules on adsorption isotherm modeling using activated carbon. Desalination, 264, 97-101.

19. Mishra S.P., Patra A.R., Das S. 2021. Methylene blue and malachite green removal from aqueous solution using waste activated carbon. Biointerface Research in Applied Chemistry, 11(1), 7410-7421.

20. Nnaji N.J., Okafor N.I., Ekwonu A.M., Osuji O.U., Okwukogu O.O., Okoye O., Anozie A.I., Anene S.C., Ehiri R.C., Onuegbu T.U. 2021. Cashew nut testa tannin resin - preparation, characterisation and adsorption studies. Journal of Taibah University for Science, 15(1), 170-183.

21. Ovchinnikov O.V., Evtukhova A.V., Kondratenko T.S., Smirnov M.S., Khokhlov V.Y., Erina O.V. 2016. Manifestation of intermolecular interactions in FTIR spectra of methylene blue molecules. Vibrational Spectroscopy, 86, 181-189.

22. Rekha Singh T.S.S., John O.O., James A.S., Joshua N.E. 2020. Evaluation of methylene blue sorption onto low-cost biosorbents: Equilibrium, kinetics, and thermodynamics. Journal of Chemistry, 1-11.

23. Salahshoor Z., Shahbazi A. 2014. Review of the use of mesoporous silicas for removing dye from textile wastewater. European Journal of Environmental Sciences, 4(2), 116-130.

24. Siddiqui S.I., Rathi G., Chaudhry S.A. 2018. Acid washed black cumin seed powder preparation for adsorption of methylene blue dye from aqueous solution: Thermodynamic, kinetic and isotherm studies. Journal of Molecular Liquids, 264, 275-284.

25. Silverstein R.M., Webster F.X., Kiemle D.J. 2005. Spectrometric identification of organic compounds, 7th ed. New York, John Wiley \& Sons., 106. 
26. Tran H.N., Wang Y.F., You S.J., Chao H.P. 2017. Insights into the mechanism of cationic dye adsorption on activated charcoal: The importance of $\pi-\pi$ interactions. Process and Safety Environmental Protection, 107, 168-180.

27. YoussefA.M., El-Khouly A.A.,Ahmed A.I., El-Shafey E.I. 1995. Changes in the adsorption properties of activated carbon due to partial oxidation of the surface. Adsorption Science and Technology, 12, 211-219.
28. Yuan N., Cai H., Liu T., Huang Q., Zhang X. 2019. Adsorptive removal of methylene blue from aqueous solution using coal fly ash-derived mesoporous silica material. Adsorption Science and Technology, 37(3-4), 333-348.

29. Zhu Y.N., Wang D.Q., Zhang X.H., Qin H.D. 2009. Adsorption removal of methylene blue from aqueous solution by using bamboo charcoal. Fresenius Environmental Bulletin, 18(3), 369-376. 